\title{
Artes plásticas no Nordeste
}

\author{
ANA MAE BARBOSA
}

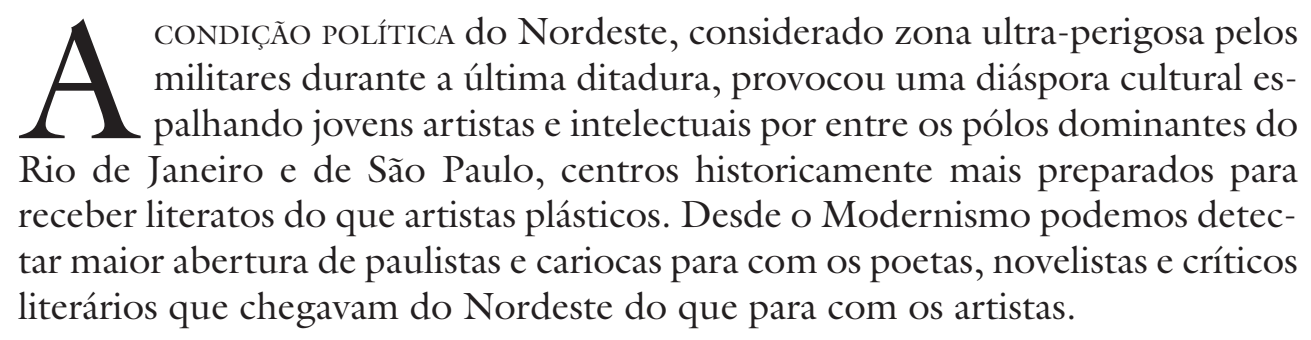

Cícero Dias e Antonio Bandeira, embora tenham sido agraciados com alguns elogios da crítica hegemônica do Sul, nunca tiveram nas Artes Plásticas um reconhecimento na mesma altura que tiveram José Lins do Rego, Graciliano Ramos, Manuel Bandeira, Álvaro Lins, Jorge de Lima, Raquel de Queiroz, na Literatura. Poucos aplausos e muito vácuo fizeram com que tanto Cícero Dias quanto Antonio Bandeira imigrassem para a Europa, onde obtiveram sucesso mais contínuo e consistente. Mesmo assim foi preciso muita tenacidade de uma nordestina, Vera Novis, para publicar, no ano passado, seu belíssimo livro sobre Antonio Bandeira. Foram quase sete anos de batalha, que começaram quando trabalhamos juntas no MAC-USP. Todos a quem recorríamos reconheciam a qualidade antecipadora da pintura de Bandeira; os colecionadores disputam seus quadros, mas seu nome não faz parte do campo de ação publicitária dos críticos que ditam a moda.

A obra de artistas como Carlos Oswald, Aloísio Magalhães ou Lula Cardoso Ayres vai ter que esperar por outros teimosos críticos, fora do circuito dominante, como Vera, ou virar tese de algum estudante de pós-graduação para terem os livros e/ou as retrospectivas que merecem. Espero que não demore tanto tempo como no caso de Vicente do Rego Monteiro, o mais original dos modernistas brasileiros. Tendo-se em vista que originalidade era um dos valores máximos do Modernismo, demorou muito para que sua obra atingisse um patamar além do mero reconhecimento. Isto só se deu na década de 70 porque o poder nas Artes Plásticas naquela época estava nas mãos de um homem sem preconceitos, um historiador de olhar plural, Walter Zanini, que organizou uma inesquecível retrospectiva de Rego Monteiro no MAC-USP.

Acredito, entretanto, que certa dose de exclusão e distância dos artistas do Nordeste com relação ao centro de poder das Artes Plásticas os torna hoje os mais bem preparados artistas para dialogarem com as correntes contemporâneas da multiculturalidade. Afastados do centro por discriminação política durante a ditadura militar e, depois, pelas ditaduras do mercado e da crítica que teimam em só promover o abstrato, o matérico, o minimal, a arte clean correspondente 
ao código europeu ou norte-americano branco, os artistas do Nordeste continuaram a desenvolver sua própria cultura visual, rejeitando ou assimilando as correntes internacionais com autonomia pessoal e não por indução, construindo uma trama de diversidade visual incomum, com qualidade, apontando para um pós-colonialismo muito mais definido que nas regiões dominadoras do país.

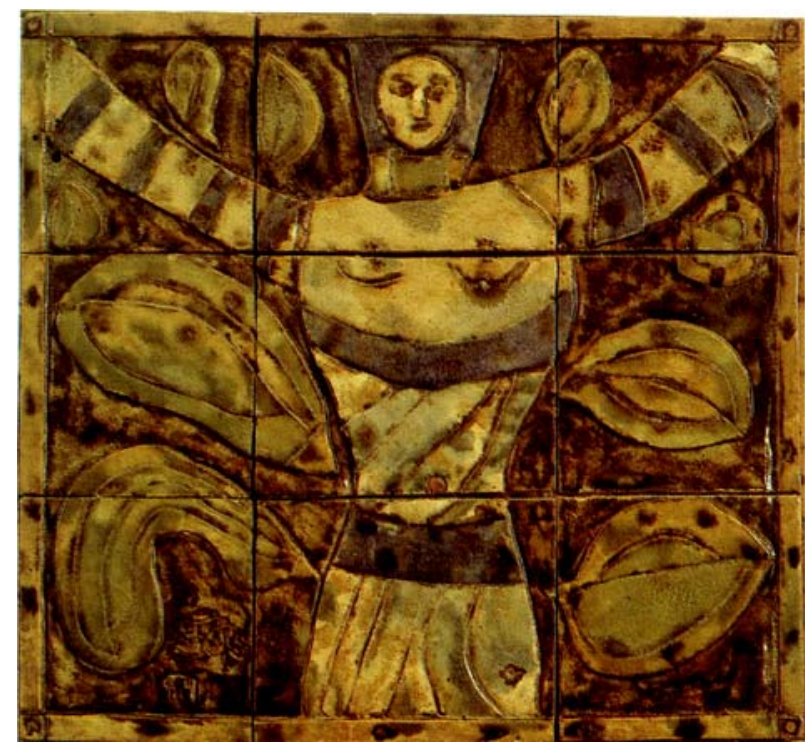

Francisco Brennand (Recife, PE 1927) São Sebastião, 1974 cerâmica vitrificada, $125 \times 113-$ col. do artista

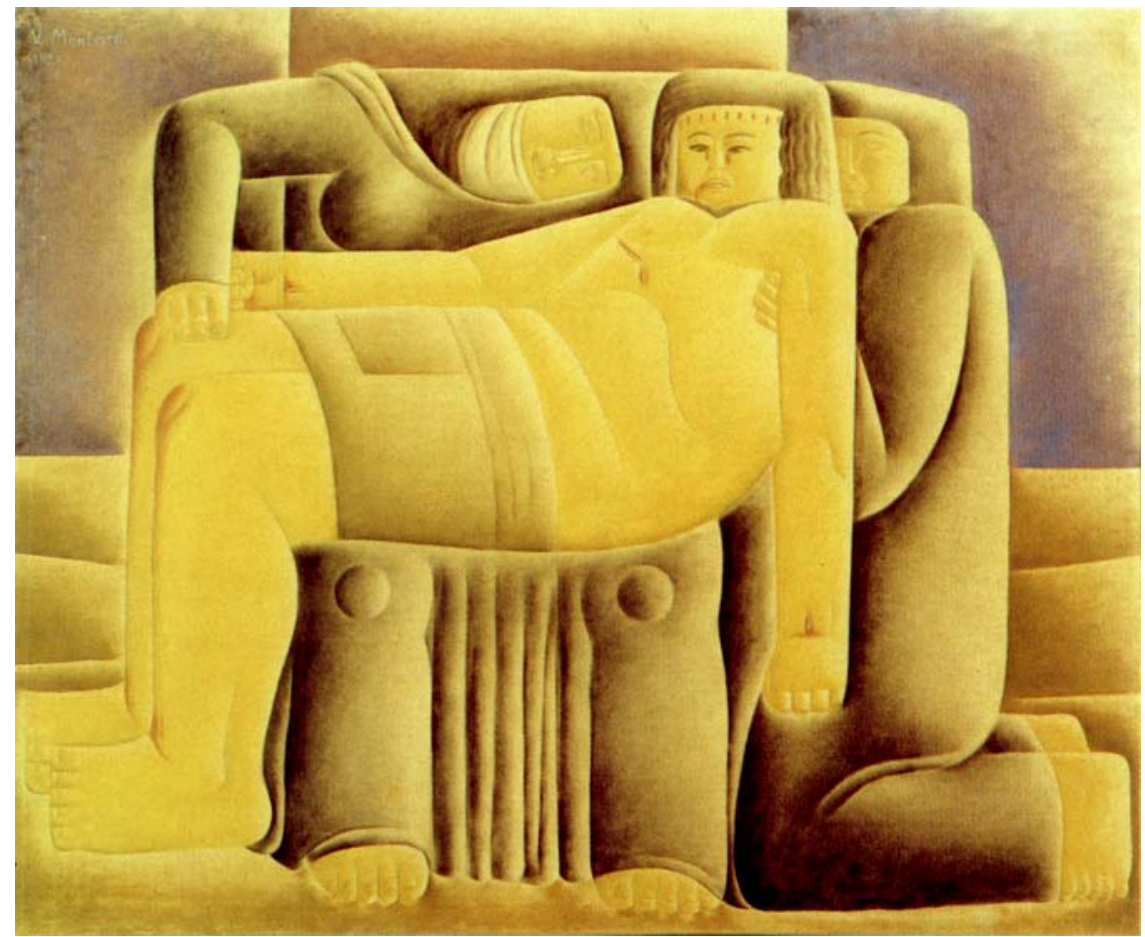

Vicente do Rego Monteiro (Recife, PE, 1899-1970) Deposição, c.1966 óleo sobre tela, $109 \times 134$ - col. MAC-USP 
No caso de Pernambuco, a ação de duas brilhantes cabeças pensantes - por sorte, divergentes entre si -, Ariano Suassuna e Jomard Muniz de Britto, foi muito benéfica. De um lado, temos Ariano Suassuna, dramaturgo famoso no Sul e no exterior que, como professor de Estética de várias gerações de estudantes da Universidade Federal de Pernambuco, defendia uma abordagem cultural voltada para a visualidade do meio circundante, para a mitologia da terra e para uma narrativa imaginante, que veio a constituir o que ele denominou Movimento Armorial. Do outro lado, Jomard Muniz de Britto, também com enorme influência na formação da mentalidade da juventude da Paraíba, de Pernambuco e do Rio Grande do Norte, encarregou-se da divulgação crítica das teorias da pós-modernidade. Como artista, seus vídeos e suas performances têm chamado a atenção dos estudantes para a existência de uma linguagem internacional, enquanto Ariano os desperta para verem ao seu redor. É neste jogo dialógico, no espaço intercultural dessas duas posições, no trânsito entre elas que hoje estão sendo definidas as singularidades da Arte, até no Primeiro Mundo.

As linhas que demarcam as diferenças culturais podem ser estabelecidas pelo consenso ou pelo conflito, mas, em ambos os casos, a discussão aberta que voltou a ser praticada no Recife - graças, principalmente, a esses dois intelectuais - tem buscado

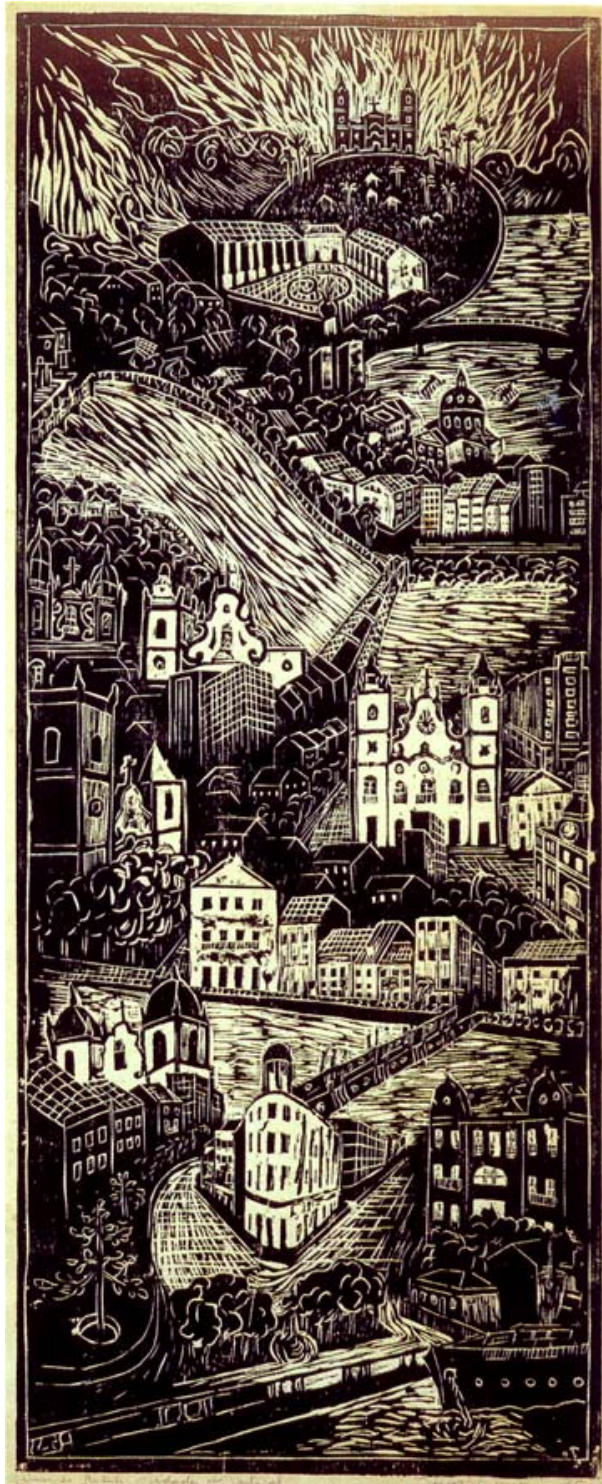

Thereza Carmem Duarte (Recife, PE, 1931), Olinda e Recife, 1965 -xilogravura, $115 \times 58$ col. particular aclarar as definições de tradição e pós-modernidade, realinhando os limites entre Arte Popular e Arte Erudita, entre o público e o privado e, principalmente, desafiando as noções de desenvolvimento e progresso.

Ariano e Jomard vêm operando para a geração atual o que duas outras escolas pernambucanas operaram para a minha geração. Uma foi a escola de um homem só, Abelardo Rodrigues, que não apenas como colecionador didata mas, principalmente, como formador de opinião da juventude, construiu uma visão sincrética entre barroco e Modernismo, antecipadora da contemporaneidade. A outra escola informal de Arte e Estética foi o Gráfico Amador, felizmente já estu- 
dado na tese de Guilherme Cunha Lima, defendida na Inglaterra. No Gráfico Amador, especialmente Aloísio Magalhães, Orlando da Costa Ferreira, Gastão de Holanda e José Laurênio de Melo foram os introdutores de minha geração às ambigüidades do Modernismo no que se refere às relações entre Arte e Design. A aprendizagem assistemática, prazerosa, realizada através da práxis que associava o ver, o fazer e discussões acaloradas que as duas escolas ofereciam, veio a ser sistematizada em termos de métodos e concepções sobre Ensino da Arte na Escolinha de Arte do Recife, da qual Noemia Varela, em parte motivada pelo inconsciente coletivo modernista da época, com alguma dose de influência de Augusto Rodrigues, a quem, em contrapartida, influenciou mais tarde, e principalmente por sua invulgar cultura educacional e sensibilidade, comandou a modernização do ensino da Arte no Nordeste com enorme abertura para a pluralidade de expressão.

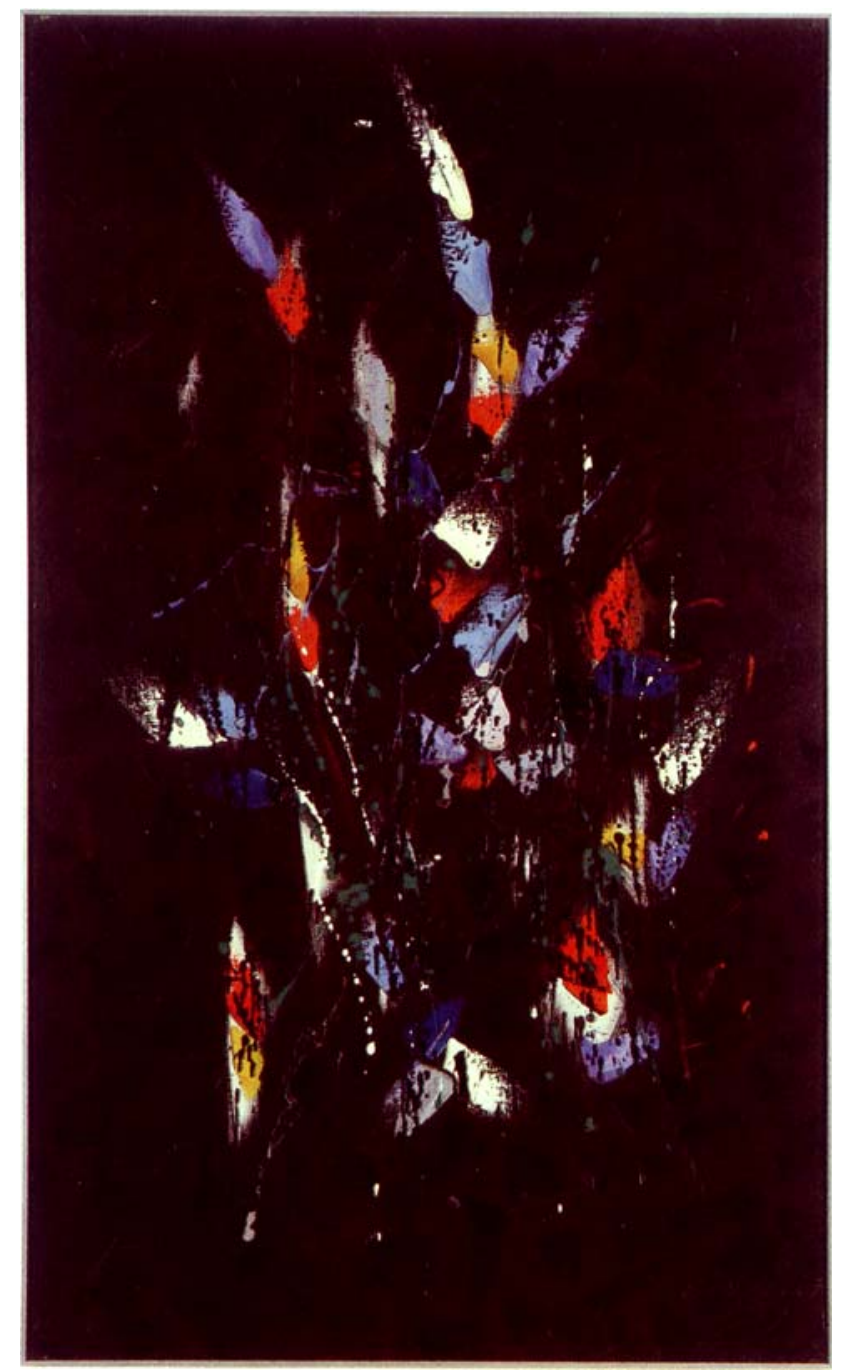

Antonio Bandeira (Fortaleza, CE, 1922 - Paris, França, 1967) Flora noturana, 1959 - óleo sobre tela $162 \times 96-$ col MAC-USP 
O mesmo olhar plural tem presidido as atividades da melhor escola contemporânea de artistas do Nordeste, a Oficina Guaianazes, que espero continue plural agora que foi incorporada à Universidade Federal de Pernambuco. Em termos de pluralismo, a Oficina Guaianazes corresponde, para o Nordeste, ao que significou para o Sul dos Estados Unidos o Grupo Tamarind, hoje funcionando também em uma Universidade, a de New Mexico, em Albuquerque.

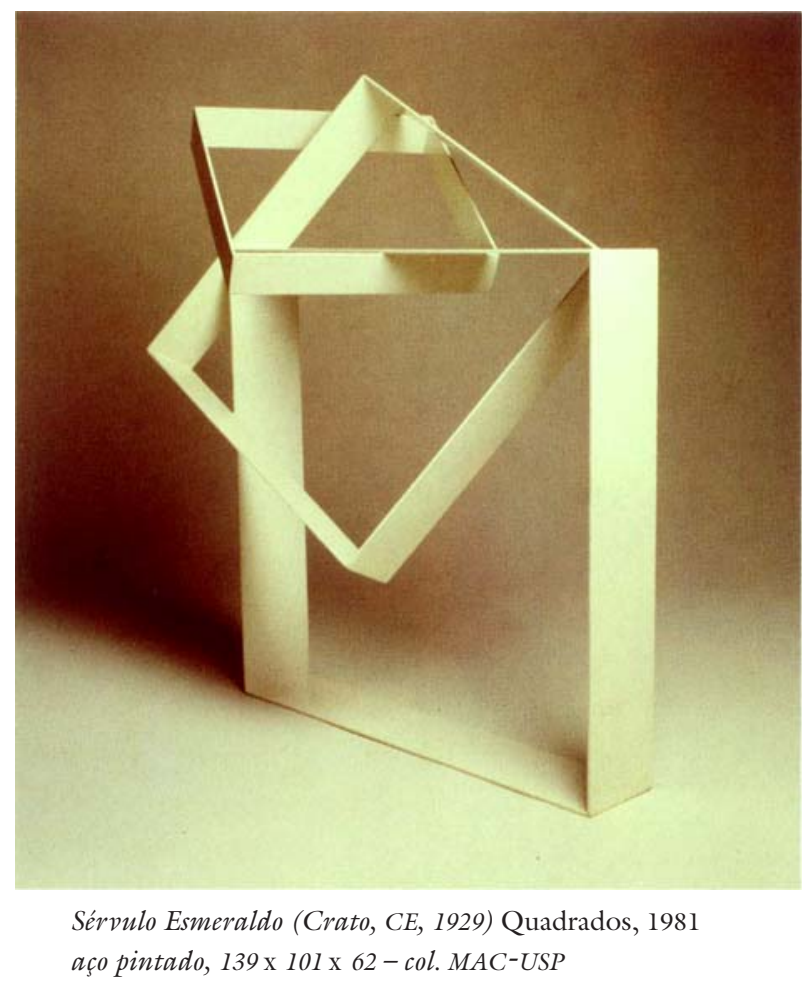

Nem nos piores momentos políticos os artistas nordestinos se submeteram à ditadura do Sul, que por anos vem valorizando quase que exclusivamente a genealogia minimalista, abolindo o figurativo das exposições, e condenado ao pecado qualquer adequação da imagem ao referente, isto nos dias de hoje quando, como diz Graig Owens (1), os artistas já não põem entre aspas o referente, mas trabalham no sentido de pô-lo em atividade, problematizando-o.

Mesmo nos tempos heróicos de Luiza Erundina na Prefeitura de São Paulo, que foi tão eficiente e plural no que concerne às políticas de saúde, de educação, de moradia e de bibliotecas, o Centro Cultural São Paulo, da Secretaria de Cultura do Município, na área de Artes Plásticas, só exibia o que a crítica modernista greenbergiana - já um pouco atrasada - considerava vanguarda, abolindo completamente o figurativo.

É verdade que a produção concreta, neoconcreta, abstrata e conceitual deu ao Brasil muito do que há de melhor em Artes Plásticas até agora. No Nordeste, podemos nos referir ao trabalho de Sérvulo Esmeraldo, Montez Magno, Paulo Bruscky, José de Barros, e há muitos mais. 
Entretanto, a obsessão minimalista com a pura opticalidade que domina os poderosos exclui outras tendências, tornando-se uma espécie de conservadorismo da vanguarda, impedindo que outras manifestações floresçam.

Os críticos guardiões da absoluta autonomia da Arte decretaram pela intransigência sua submissão a uma única tendência e poucas variáveis próximas, o que podemos chamar, parodiando Graig Owens, de minimalismo degenerativo. Aos poucos, tornaram-se incapazes de avaliar o figurativo e suas muitas contestações do real, fecharam-se mais ainda em grupos e usam de todas as armas, inclusive a violência da exclusão, para defenderem seus direitos de proprietários de uma corrente estética e de alguns artistas.

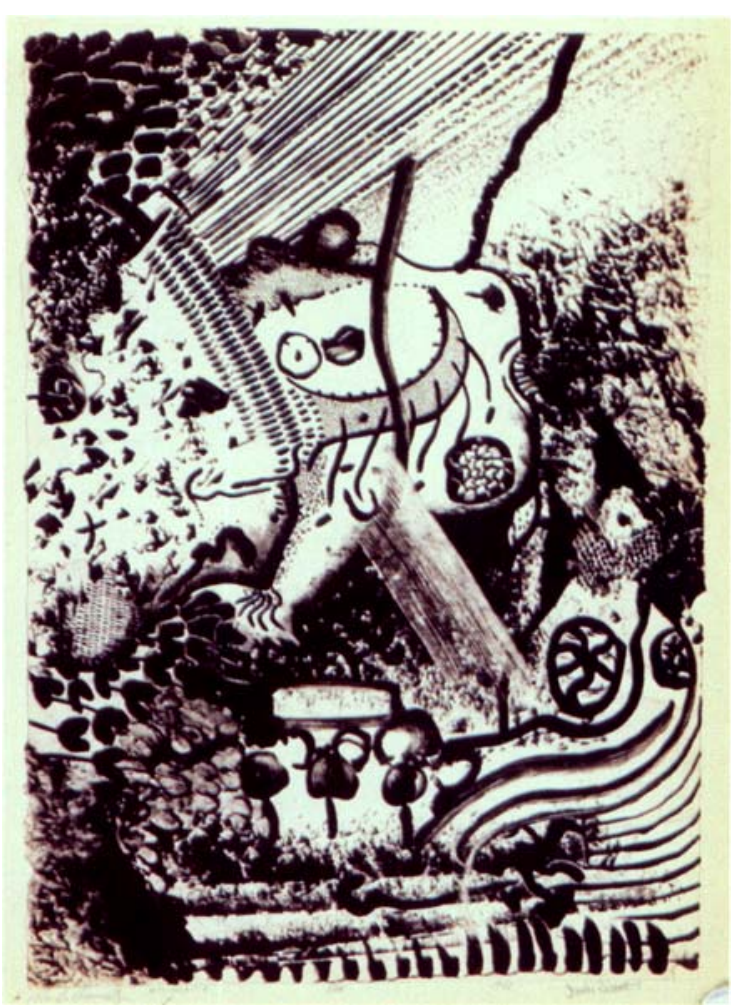

Paulo Bruscky (Recife, PE, 1949) Estudo I, 1988 heliografias/papel, $68 \times 50-c o l$. MAC-USP

A multiculturalidade do Nordeste muito beneficiar-se-ia com a ampliação de espaço crítico e de visões alternativas, tão urgente necessárias nas Artes Plásticas no Brasil. Os críticos de Arte batem nos ombros uns dos outros, num acordo tácito de silêncio ou sinal de convênio elogio. Os ricos debates que explodem aqui e ali na área da Literatura não têm eco nas Artes Plásticas, embora a Teoria da Arte esteja tomando a Teoria Literária de empréstimo já há bastante tempo. $\mathrm{O}$ último constru- to teórico específico das Artes Plásticas foi a Iconografia de Panofsky. De lá para cá, descons- trucionismo, neoestruturalismo, multiculturalidade, estética da recepção, estética antropológica, estética cibernética etc., assimilados de outras áreas, têm buscado significação no domínio visual, forman-

do não um melting pot, como acusam os puristas, mas uma colcha de retalhos teórica bem recortada e definida, garantindo a pluralidade de valores. A crítica de Arte e as instituições no Brasil necessitam de uma redefinição cultural para serem capazes de avaliar as diferenças. O novo Centro de Arte Contemporânea da Universidade de Pernambuco está dando exemplo de política cultural pluralista e muito se espera dele no Recife. Também aberto às diferenças tem atuado o Núcleo de Arte Contemporânea da Universidade da Paraíba. Têm havido acusações à ditadura do minimalismo no sentido de haver transformado a Arte em nosso país numa mera cópia dos padrões europeus e norte-americanos, atestando 
a condição periférica do Brasil (2). Isso, para mim, não tem a menor importância. Para a contemporaneidade, transformação, apropriação, hibridismo, tradutibilidade, canibalização são a norma.

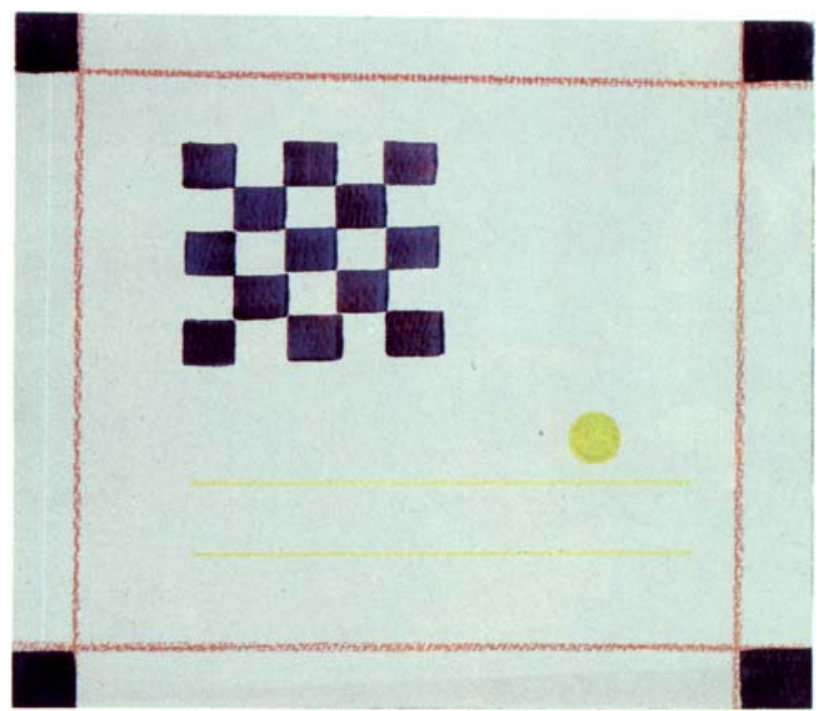

Montez Magno (Timbaúba, PE, 1934) Sem título, 1973 gauche e crayon s/ papelão, $24 \times 28-$ col. MAC-USP

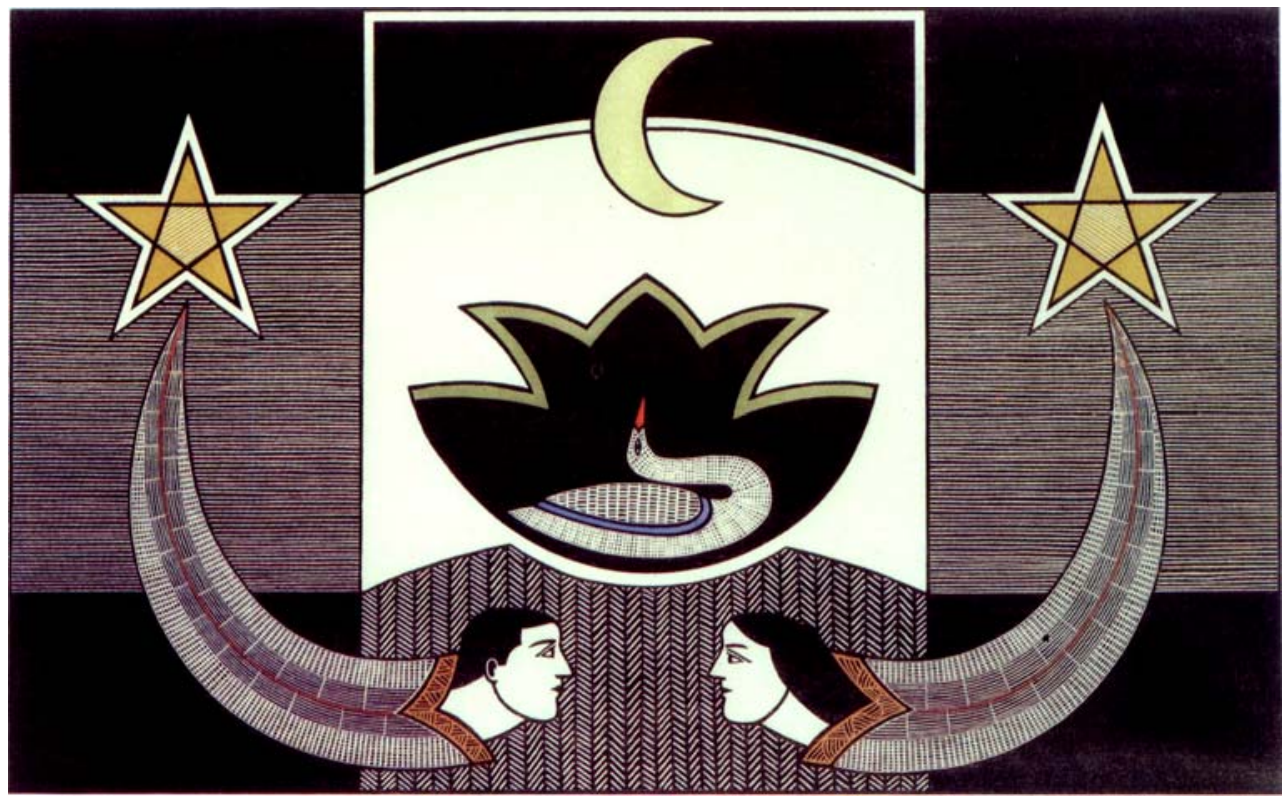

Gilvan Samico (Recife, PE, 1928) Primeira homenagem ao cometa, 1985 xilogravura, 54 x $90-$ col. do artista

O que me incomoda na crítica hegemônica do Rio de Janeiro e de São Paulo é a ausência de olhar plural. Projetos que poderiam ter se tornado influentes em termos de Brasil terminam limitados pela falta de capacidade analítica para a diversidade, embora se espalhem geograficamente. É o caso do Centro 


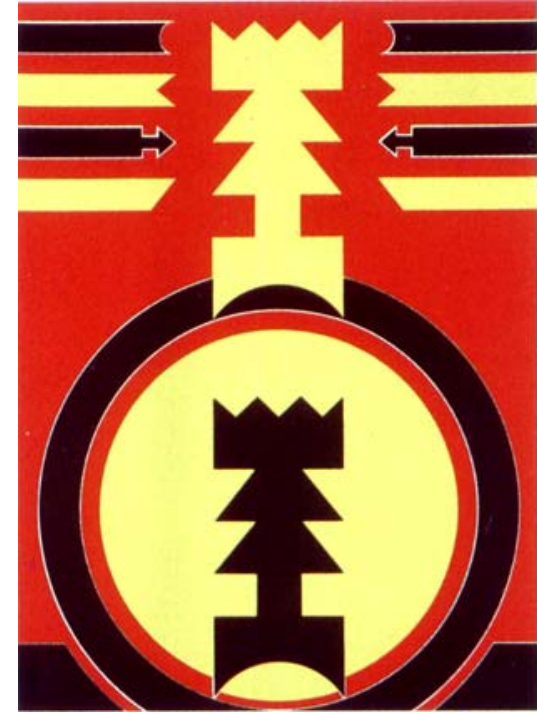

Rubem Valentim (Salvador, BA, 1922 - São Paulo, SP, 1991) Emblema IV, 1989 - serigrafia a cores s/ papel, $100 \times 70-$ col. MAC-USP
Cultural Itaú e do projeto Antarctica-Folha. Este último, muito promissor no sentido do reconhecimento do outro, operou positivamente em várias áreas do Brasil, mas no Nordeste histórico foi tímido. Na seleção dominou a política de confirmação do reconhecimento. Faltou o olhar que vê onde os outros ainda não viram. Dos três escolhidos, Efraim Almeida mora no Rio e expôs no MAM-SP, no Paço Imperial e na Galeria Camargo Vilaça; José Rufino, que já havia sido premiado em São Paulo e participado de exposições até no exterior, era considerado artista do primeiro time da região antes de ser descoberto pelo Projeto AntarcticaFolha, que tanto alardeou sua missão de resgate dos jovens desconhe-cidos, a ser feita através da mega-exposição organizada em

São Paulo durante a Bienal 96, uma espécie de Aperto nacional.

Talvez o viés da pré-seleção tenha limitado a ação da curadora, a inteligente e articulada Lisette Lagnado, que produziu uma exposição sobre o new ready

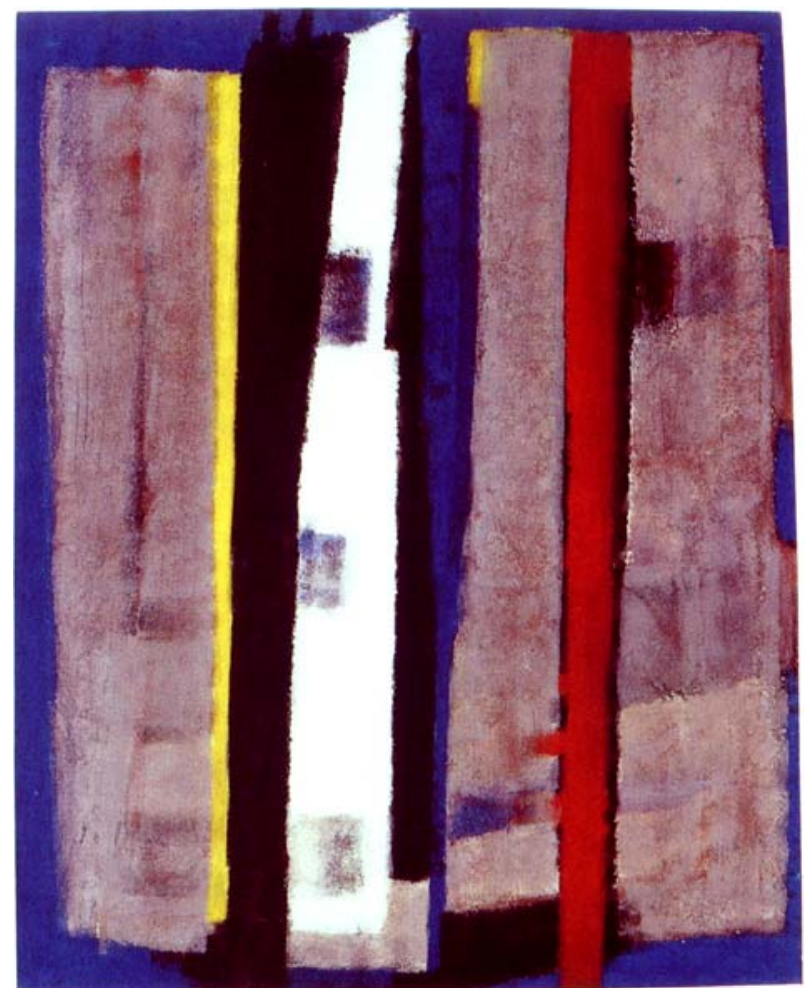

Roberto Lúcio de Oliveira (João Pessoa, PB, 1941) Tapumo XIV, 1992 - acrílico s/ tela, 150 × 120 col. do artista made em 1993, premiada como a melhor daquele ano. Conta-se em Recife, onde nenhum artista foi escolhido (Patrícia Azevedo nasceu em Recife, mas vive e trabalha em Minas Gerais), a piada de que o auxiliar de curadoria, que lá foi para fazer a primeira seleção dos artistas, estava preocupado em encontrar um equivalente a Arthur Bispo do Rosário no Nordeste. Este sim foi "descoberto" por Frederico Moraes, um dos poucos críticos no Brasil capaz de não só descobrir Bispo, mas também de avaliar o figurativo.

$\mathrm{O}$ que ocorreu com o Nordeste, todavia, não contamina todo o projeto, que teve muitos pontos positivos. Um deles foi mostrar ao poder cen- 
tral as condições mais que precárias nas quais trabalham os jovens artistas do outro Brasil.

Um dos curadores escreveu um artigo na Folha de S. Paulo contando o caso de um candidato à exposição Antarctica-Folha a quem pediu para ver alguns outros trabalhos; o artista respondeu pedindo tempo, pois os outros trabalhos estavam em casa de uma tia e ele não tinha dinheiro para pagar o ônibus a fim de ir pegá-los. Este curador foi capaz de ver, reconhecer e registrar as diferenças de contexto, a até de se comover com elas (4).

Curadores começam a deixar de ser anjos de pureza (5) e a desenvolver uma linguagem que fala com em lugar de uma linguagem que fala para. A pós-modernidade da curadoria reside na comunicação autêntica e plural e não mais no discurso unilateral, unívoco e individual do colonialismo interno. Não quero dar a impressão errada de que sou regionalista ou localista, reclamando dos internacionalistas. Seria uma mistificação, inclusive por estar escrevendo este artigo enquanto ensino numa universidade norte-americana, que se pretende internacional (6).

Entretanto, para ser internacional é necessário não apenas estar amplamente informado pela Internet mas, principalmente, ter flexibilidade para perceber o outro embebi-

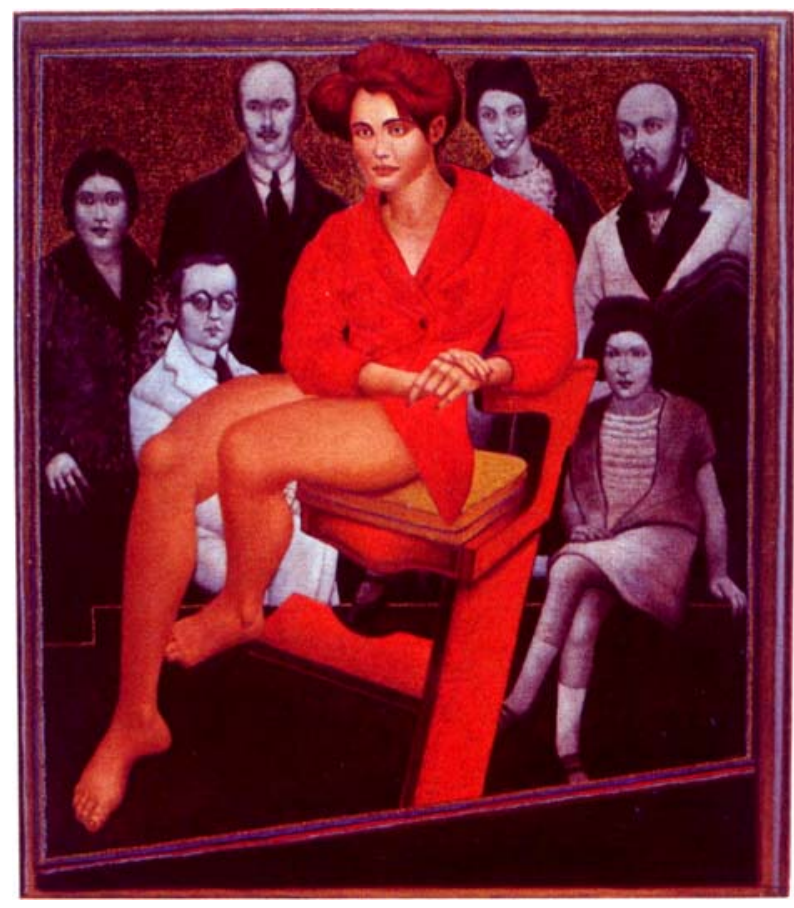

João Câmara (João Pessoa, PB, 1944) O espelho da memória, 1992 óleo s/ tela, $160 \times 140-$ col. do artista

do em seus próprios valores e não previsualizado ou prejulgado por um único código, muito menos pelo código hegemônico do poder.

A pluralidade entre os jovens artistas do Recife, que conheço melhor que outras cidades do Nordeste, vem sendo nutrida pela pluralidade de seus mestres: João Câmara, Francisco Brennand, José Cláudio, Montez Magno, Paulo Bruscky, Gilvan Samico, Reynaldo Fonseca, Abelardo da Hora.

As relações entre o figurativo e o real, por exemplo, são pouco amadurecidas na atualidade no eixo Rio-São Paulo em virtude da ditadura da neovanguarda (7). No Nordeste, metamorfoseiam-se e diferenciam-se de artista para artista. O figurativo como representação no Nordeste distancia-se das preocupações da crítica modernista, que se ateve a considerações acerca do realismo visual, para 
traduzir as inquietações da crítica contemporânea com as múltiplas manifestações do realismo perceptual. Trata-se de um figurativismo que desacredita o real com a mesma força que o abstracionismo, embora menos literalmente.

Comecemos por Reynaldo Fonseca que, como Balthus, é um cético do realismo, pois reduz a figura a um esquema visual sempre presente em sua obra e ressalta a narrativa. Ele ficcionaliza a representação, enquanto João Câmara ficcionaliza a objetividade do real. Câmara trabalha o reverso cultural da imagem, o ato de pintar permanecendo como mediador entre o observador e o assunto. Sua pintura protege o tema contra o olhar objetivo. É em virtude da diversidade, associada à alta qualidade da construção simbólica dos mestres, que se pode ter hoje no Recife jovens artistas que, afirmando sua linguagem pessoal, permanecem fora do circuito da franchise crítica que decide as artes no país.

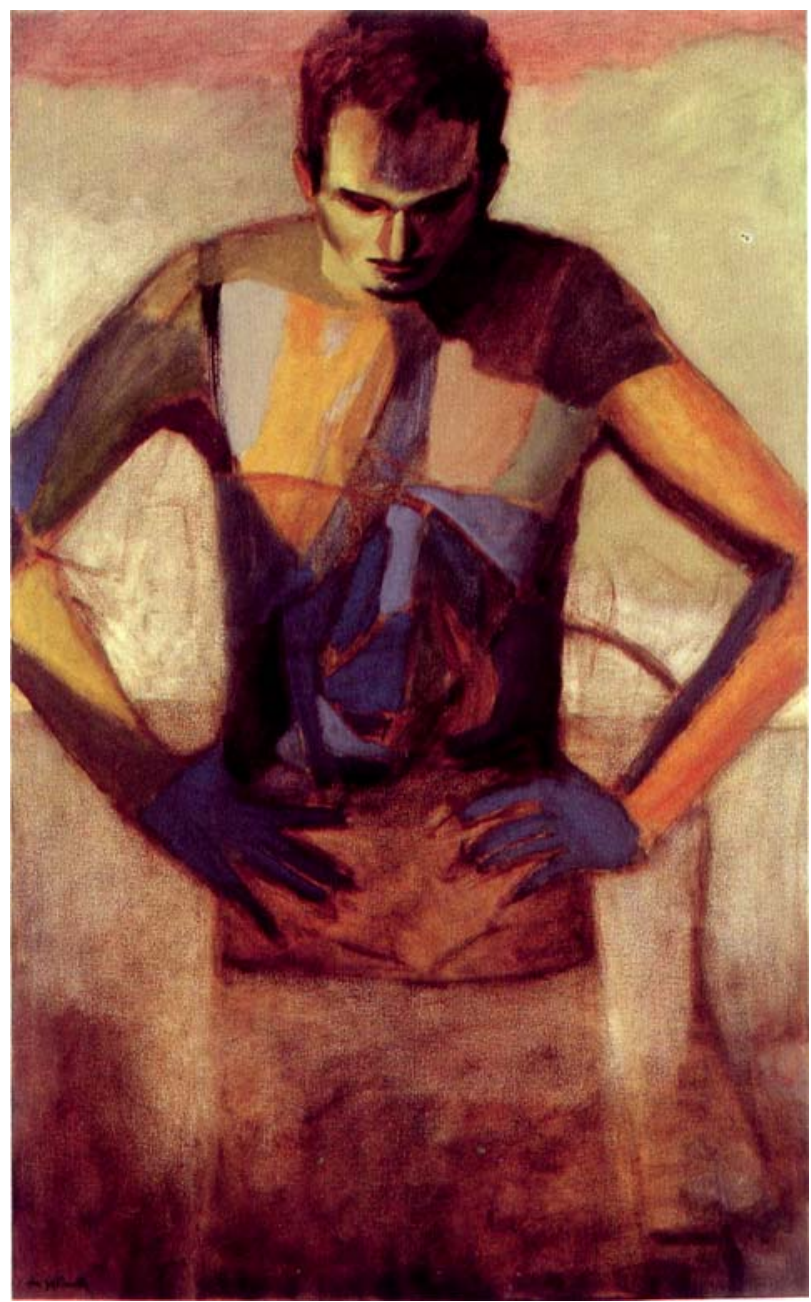

Gil Vicente (Recife, PE, 1958) Homem com as mãos azuis, 1996 óleo s/ tela, 130 x $80-$ col. do artista

Gil Vicente é um exemplo. Seu ponto alto é o metaretrato da Arte em Pernambuco através da representação dos artistas, seus amigos e influenciadores, 
representação esta que revela no tratamento da superfície pictórica índices que decodificam a Arte dos representados. Por outro lado, as figuras em sua pintura significam principalmente através do espaço vazio entre elas, ou que as cerca, uma sofisticação de linguagem muito atual.

Já a obra de Sebastião Pedrosa, que ele próprio teima em esconder, é radicalmente diferente. Suas discretas caixas-esculturas, trazendo à memória o culto japonês do invólucro e mitologias nordestinas ocultas, operam um hibridismo cultural sedutor.

Outra diferença entusiasmante é Romero Andrade Lima, conhecido em São Paulo principalmente pela cenografia e animação cultural. Contudo, de maior importância e densidade é sua escultura, resultante sincrética da introjeção da linguagem construtiva contemporânea e da saga cultural do Nordeste. Isso o torna herdeiro do valioso sincretismo de Rubem Valentim e Gilvan Samico. Por sincretismo, quero significar uma tal relação simbiótica de duas culturas que torna o objeto reconhecível como seu por ambas as culturas que o permeiam (8).

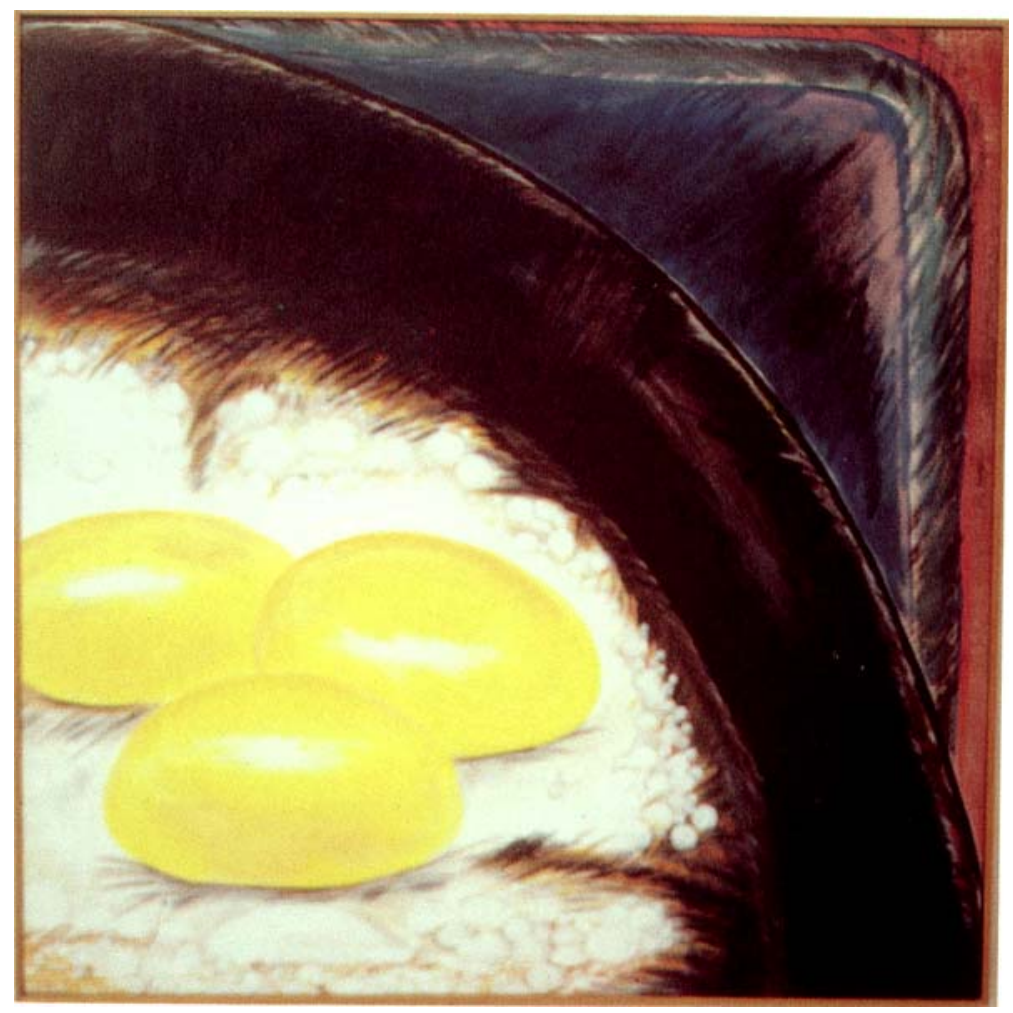

Virginia Colares (Recife, PE, 1952) No frigir dos ovos, 1996 acrílico s/ tela, $100 \times 100-$ col. do artista

O vídeo deconstrucionista da obra de Rubem Valentim, feito por Sílvio Zamboni, nos mostra o artista assimilando o geometrismo construtivo da arquitetura de Brasília, entrecruzando-o com os desenhos-símbolos do candomblé. O 
mestre do sincretismo pernambucano é, sem dúvida, Gilvan Samico, associando a dicção das imagens populares da literatura de cordel ao espaço clean do Modernismo. Sincretismo da mesma natureza preside a obra de Romero, introjetando a linguagem baubausiana de um Oskar Schlemmer com o armorialismo de Ariano Suassuna, mas construindo objetos de definida inventiva pessoal.

Para sublinhar ainda mais as diferenças, quero ressaltar o vigoroso trabalho de Paulo Meira, inscrito na reconstrução pós-moderna da serialidade. Também a respeito de diversidade, é preciso lembrar os trabalhos de Luciano Pinheiro, José Patrício, Adão Pinheiro, Crisaldo Moraes, Ismael Caldas, Roberto Lúcio (Pernambuco) e Miguel dos Santos (Paraíba).

Reflexão destacada merece a Arte das mulheres. No meu tempo, havia muitas artistas mulheres no Recife. O cânone histórico, implacável com o feminino, passou uma borracha na maioria. Guita Charifker e Maria Carmem continuam sendo reconhecidas e merecidamente comemoradas. Reclamo também para Thereza Carmem Diniz alto reconhecimento pela maestria e sutileza de sua gravura e destaco em sua obra a magnífica construção imagética das relações espaciais e arquitetônicas entre o Recife e Olinda, hierarquizadas e sensualmente representadas numa xilogravura que articula a influência da verticalização da gravura oriental e as linhas definidas, de corte profundo, da gravura popular nordestina (Olinda e Recife, 1965).

O movimento feminista nas Artes obrigou a revisão dos cânones de valor da Arte contemporânea e dos historiadores de Arte. Gombrich, por exemplo, não cita nem menciona qualquer artista mulher em sua famosa História da Arte, largamente usada nas Escolas de Arte de todo o mundo ocidental, nas quais estudam, principalmente, mulheres. Fato inadmissível pela Nova História da Arte. Entretanto, no Brasil, muitas artistas mulheres ainda temem o adjetivo feminino, porque, como lembra Lucy Lippard (1995), "este assunto, esta admissão de consciência sexual tem tradicionalmente sido tomada como sinônimo de inferioridade" (9). É por isso que, no eixo Rio-São Paulo, as mulheres artistas bem sucedidas se recusam a participar de exposições adjetivadas pelo feminino, embora aceitem participar de exposições de mulheres nos Estados Unidos, algumas vezes em museus dedicados só à Arte das mulheres.

No Nordeste, ao contrário, as mulheres estão se organizando para expor e até mesmo enfrentando o resgate de temas menosprezados por serem considerados femininos ou domésticos. Esta é mais uma vantagem flexibilizadora para o Nordeste, resultante de ter sido relegado por muitos anos à heterogeneidade das margens. A audiência feminina tem aumentado no Nordeste, o que tem ajudado a conquistar para o trabalho das mulheres a mesma consideração outorgada aos trabalhos dos homens.

Galerias dirigidas por mulheres têm procurado tornar visível a Arte das mulheres, organizando exposições e debates como o que presenciei na Galeria Artespaço, de Boa Viagem, em agosto de 1996. 
O trabalho extremamente sério e inovador de artistas mulheres está sendo reconhecido, como é o caso de Viga Gordilho e Norma Couto (Bahia), Alice Vinagre (Paraíba), Oriana Duarte, Bete Gouveia, Cristina Machado, Angela Poluzi, Virginia Colares, Clementina Duarte e Cristina Ribeiro (Pernambuco), Regina Guedes (Rio Grande do Norte), Dodora (Ceará). As mulheres no Nordeste estão impondo sua condição ao mundo das Artes, e não apenas criando nos termos estabelecidos pelos homens e pelo Primeiro Mundo das Artes no Brasil.

Estranho que no Nordeste a fotografia tem sido pouco explorada. Tratase de um meio cuja gramática visual se coaduna com o realismo codificado, a imanência fenomenológica e o estranhamento psicológico que vem designando a Arte contemporânea. A última Bienal do Whitney Museum de New York foi dominada pela fotografia, e é nela que se realiza um dos maiores artistas brasileiros atuais: Sebastião Salgado. Ressalto no Nordeste a obra fotográfica de Mario Cravo Neto e a fotografia pictórica de Ana Mariani, embora tenha procurado neste artigo evitar falar dos nordestinos de São Paulo ou do Rio de Janeiro, mesmo daqueles resistentes à assimilação pelo código hegemônico.

Quis homenagear a resistência em permanecer geográfica e institucionalmente na periferia do poder e, principalmente, a flexibilidade dos intelectuais e artistas que vivem no Nordeste em coexistir com diferentes códigos culturais e estéticos e serem capazes de avaliar e julgar cada um dos códigos, respeitando os valores enunciados no próprio código e no seu contexto.

A Arte hoje, cuja autonomia vem sendo relativizada pelos estudos culturais, demitiu a onipotência dos modelos modernistas europeu e norte-americano branco e clama por diversidade, por uma política da diferença. Respeito à diferença é instrumento de consciência estética no Nordeste.

Notas

1 Graig Owens. Beyond recognition: representation, power and culture, Berkeley University of California Press, 1992. Editado por Scott Bryson, Barbara Kruger, Lynne Tillman and Jane Weinstock, depois da prematura morte do autor.

2 A expressão foi tirada do título do artigo de Marcelo Coelho sobre a Bienal Brasileira: Bienal atesta condição periférica do Brasil: toda a arte brasileira parece imitação de linguagens estrangeiras, o que não diminuiu a qualidade do que se faz aqui. Folba de S. Paulo, 13 maio 1994, caderno 5, p.8.

3 Histórico Nordeste compreende Ceará, Rio Grande do Norte, Paraíba, Pernambuco, Alagoas e Sergipe. Bahia e Maranhão tornaram-se Nordeste por determinação da Sudene.

4 Omito o nome do curador porque não tenho condições de consultar o artigo e não quero comprometê-lo caso a minha informação não esteja bem precisa. 
5 Apropriação de termos usados por Vicent Kaufman em Angels of purity, revista October, n.79, p. 50, Winter 1997.

6 Contudo, sobre Arte no Brasil só encontrei na biblioteca velhos catálogos, o Dicionário de Artes Plásticas de Roberto Pontual e poucas referências nos muitos livros sobre Arte latino-americana que têm sido publicados nos Estados Unidos nos últimos dez anos.

7 Sobre neovanguarda, ver a revista Art Criticism, v.11, n.1, 1996, p.90-110, que traz o resumo de um seminário organizado em outubro de 1995 pela Universidade de Cambridge para discutir o livro The cult of the avant-garde artist, de Donald Kuspit. A tônica da discussão foi a diferença entre a vanguarda modernista, movida pelo break with tradition ou search for the new, comemorados por Clement Greenberg e Harold Rosenberg, e o artista da neovanguarda, ironicamente conformista, usando Arte não só para se tornar parte do stablishment mas como um fetiche vazio, uma commodity negociável. Conclusão dos debates: para o artista da neovanguarda, Arte é uma carreira cínica em lugar de desesperada e incerta, como a dos modernistas.

8 Moshe Barasch (1996), Visual syncretism: a case study, em S. Budick e W. Iser, The translatability of cultures, Stanford, Stanford University Press, 1996.

9 Lucy Lippard, The pink glass swan, New York, The New Press, 1995, p.58.

Ana Mae Barbosa é coordenadora do Núcleo de Cultura e Extensão em Promoção da Arte na Educação - ECA-USP, presidente da ANPAP, professora visitante da Ohio State University/USA

A autora agradece a Claudia Toni e Rejane Coutinho pelo trabalho de checar algumas informações contidas neste artigo e de selecionar as obras reproduzidas. "Sem a ajuda das duas, privada das fontes de referência, e contando apenas com a minha memória, seria impossível escrever este artigo". 


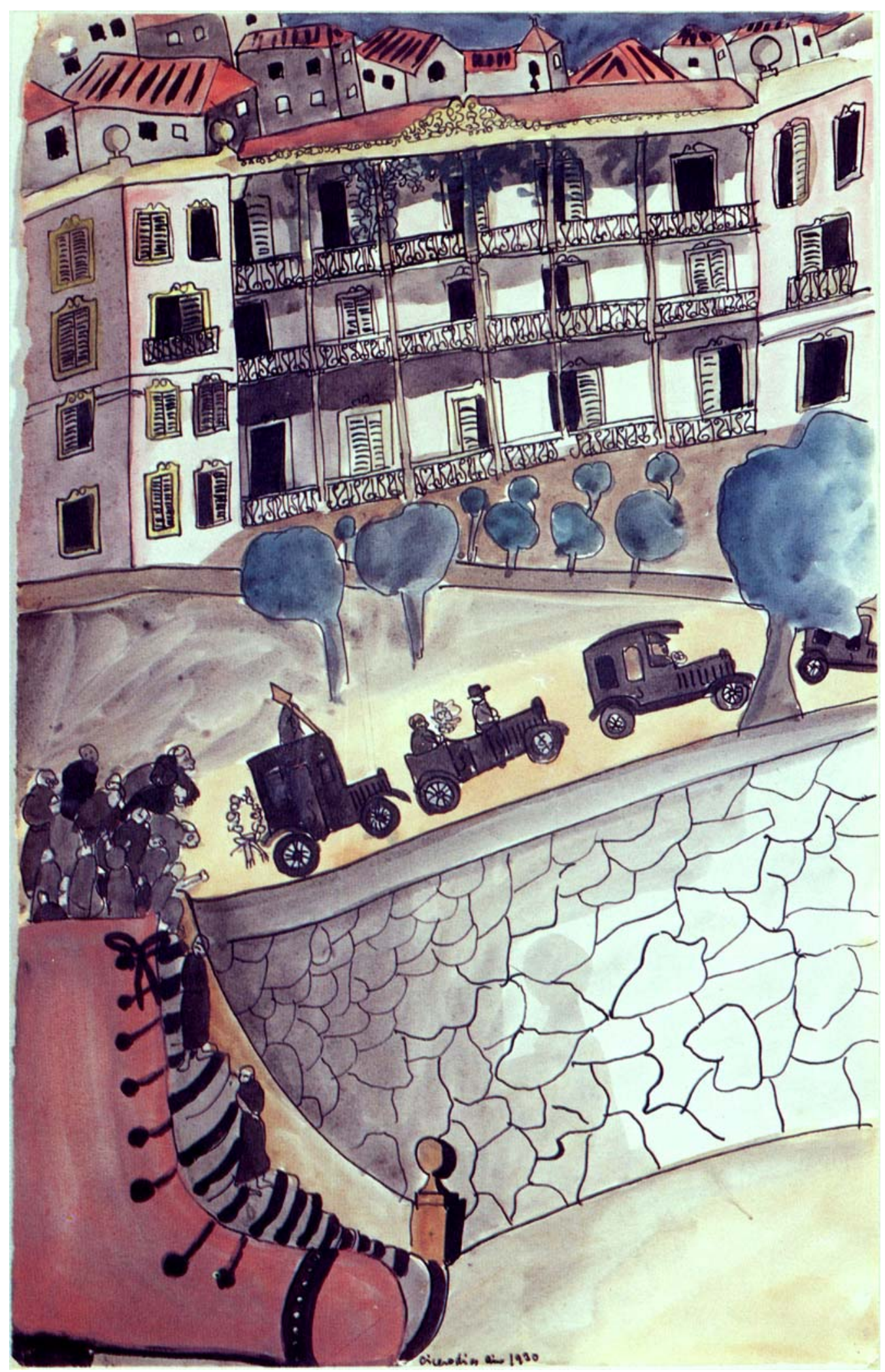

Cícero Dias (Recife, PE, 1928) Cortejo, 1930 - nanquim e aquarela s/ papel, 47 x 30-col. IEB-USP 